\title{
MEASUREMENTS OF MASS DIFFUSIVITY OF GASES IN PLASMA AND REACTION VELOCITY CONSTANT IN BLOODS* $\dagger$
}

\author{
I. TANASAWA. $\ddagger$ R. ECHIGO.§ D. R. WOTTON,"M. NOMURAT \\ and \\ WEN-JEI YANG** \\ The University of Michigan, Ann Arbor. Michigan 48104. U.S.A.
}

\begin{abstract}
A method is developed to determine the mass diffusivity of gases in plasma and the reaction velocity constant with hemoglobin in intact red cell suspensions. in human and dog blood. Oxygen, nitrogen and carbon dioxide are used. A small gas bubble is injected into a flask containing plasma or blood degassed by the use of a vacuum pump. The instantaneous bubble size is measured at certain time intervals until the bubble is completely dissolved in the liquid. Both the mass diffusivity and the reaction velocity constant are calculated from the solution of the mass transfer equation for the diffusion of a gas from a bubble into a liquid, using the initial size and measured life time of the bubble as input data. or the slope of the radius-time curves during the moment immediately following injection. Results are compared and agree well with some existing values.
\end{abstract}

\section{INTRODUCTION}

IN THE exchange of respiratory gases with the blood in the lungs and in the periphery, the primary chemical reactions of these gases take place within the red cell, not in the plasma. Experimental results have indicated that the rates of the exchange of carbon monoxide, and possibly oxygen and carbon dioxide with red cells limit, at least partially, the rate of the exchange of these gases in the lungs. Therefore, the velocities of the reactions between respiratory gases and intact red cells are of importance physiologically.

Because of the experimental difficulties arising from very rapid reaction, studies on the reactions of hemoglobin with gases are confined to a few researchers and data thus obtained are full of variety. The work of measurement of the reaction velocity constant has not sufficiently far advanced to allow adequate theoretical treatment.

A comprehensive review of the work in this field is given by Gibson (1959). In his review. a section is given on methods followed by an account of the chief reactions of hemoglobin with gases which have been studied thus far. Some inconsistencies and anomalies in the existing observations have been pointed out. According to Gibson (1959), the methods of measurement of the reaction velocity constant in hemoglobin solution may be classified into two: the flow and flash methods. The flow methods include those using a continuous flow rapid reaction apparatus by Hartridge and Roughton (1923), a reversion spectroscope by Hartridge and Roughton (1925), a photovoltaic cell and galvanometer by Millikan (1933) and the stopped-flow method by Gibson (1954). The flash methods are used to prepare mixtures of intermediate compounds of known

\footnotetext{
*Receiced 15 July 1970.

The work reported was supported by a grant from the National Institute of Health. The paper was presented at 1970 SESA Spring Meeting to be held in Huntsville. Alabama on May 19-22.

$¥$ Visiting scholar from the University of Tokyo, Japan.

$\$$ Visiting scholar from Kyushu University. Japan.

"Graduate Student Assistant of Mechanical Engineering.

\Research Associate of Mechanical Engineering.

**Professor of Mechanical Engineering.
} 
composition from hemoglobin photochemically. In spite of the effort of these investigators, the work of measurement is not yet sufficiently far advanced.

The first part of this paper deals with the determination of the reaction velocity constant in whole blood by the dissolving bubble method. The constant thus determined may be used to calculate the radius-time relation, and the rate of solution by diffusion of a gas in whole blood with reduced hemoglobin during extracorporeal oxygenation.

During extracorporeal oxygenation of blood, the process of oxygen exchange by red cell takes place according to the following steps. The oxygen gas being injected into an oxygenator forms bubbles and mixes with the blood re-circulated from a patient. The gas first transfers across the bubble wall and then dissolves into the surrounding plasma. Only a very small fraction of oxygen remains in the dissolved state in the fluid of the plasma. The vast fraction of the dissolved oxygen diffuses through the plasma toward red cells. Upon the meeting with a red cell, the oxygen then diffuses through the cell membrane. Inside the cell the combined processes of diffusion of oxygen and second-order chemical reaction with hemoglobin occurs. An identical process takes place for the re-absorption of gas emboli entrapped in human body.

Unfortunately, little is known about the mass diffusivities (or as it is sometimes called the diffusion coefficient) of gases in the plasma, and the reaction velocity constant between gases and intact red cells. There is an urgent need for experimental measurements.

Bird et al. (1962) have summarized the theories of ordinary diffusion in gases at low density and in liquids. The methods for experimental determinations of both gas and liquid diffusivities are also introduced. In 1929. Mache (1929) has proposed to use the rate of solution of a stationary bubble to estimate the mass diffusivity of air in water. Brandstaetter (1952) has repeated Mache's work and has suggested that the low mass diffusivities obtained by Mache were due to surface contamination. Liebermann (1957) and Manley (1960) have investigated the rate of solution of stationary air bubbles in partially saturated water, and have found that the rate of diffusion at small bubble diameters is lower than that theory predicts. This low diffusion rate was attributed to the presence of a minute impurity that forms a stable film around small bubbles. Houghton et al. (1962) have extended the method to determine the mass diffusivities of air, oxygen, nitrogen, hydrogen, helium. and neon and argon in water. The effects of the liquid phase has been studied by measuring the rate of diffusion of air into sodium chloride solutions, sea water and solutions of surfaceactive agents.

The second part of the present paper deals with the measurement of diffusion coefficient of dissolved gases in plasma.

\section{THEORETICAL BACKGROUND}

The radius-time and diffusion rate-time relations of a spherical gas bubble situated in plasma or whole blood have been investigated by Yang (1970), by solving the mass transfer equation in a liquid with chemical reaction. Chemical reaction between the dissolved gas and reduced hemoglobin occurs in whole blood, which is considered to be a homogeneous mixture of plasma and reduced hemoglobin in the analysis. It is confirmed by the study that the effects of convention induced by the motion of the bubble surface on the bubble radius and diffusion rate are generally very small, except during the very short time immediately preceeding the complete solution of the bubble. When the effects of surface tension and viscosity are neglected. Yang (1970) has obtained the expressions for the bubble radius and the mass diffusion rate into the liquid in dimensionless form as

$$
\begin{aligned}
\frac{\mathrm{d} R^{*}}{\mathrm{~d} t^{*}}= & \left(\frac{\partial C^{*}}{\partial r^{*}}\right)_{r^{*}=R^{*}}=-C_{\rho}^{*}\left(1-C_{\infty}^{*}\right) \\
& \left(\frac{1}{R^{*}}+\frac{\mathrm{e}^{-K * t *}}{V \pi t^{*}}+\sqrt{K^{*}} \operatorname{erf} \sqrt{K^{*} t^{*}}\right) .
\end{aligned}
$$


In equation (1), it is defined that

$$
\begin{aligned}
R^{*} & =R(t) / R_{0}, t^{*}=D t / R_{0}{ }^{2}, C^{*}\left(r^{*}, t^{*}\right) \\
& =C(r, t) / C_{S}, r^{*}=r / R_{0}, C_{\rho}^{*}=C_{s} / \rho, C_{x}^{*} \\
& =C_{\infty} / C_{S}, K^{*}=K R_{0}{ }^{2} / D,
\end{aligned}
$$

where $R(t)$ is the bubble radius; $t$, the time; $R_{0}$, the initial bubble radius; $D$, the diffusion coefficient of the dissolved gas in the liquid; $C(r . t)$, the concentration of the dissolved gas in the liquid; $C_{S}$, the concentration at saturated state; $r$, the distance from the center of the spherical bubble; $\rho$, the gas density; $C_{\infty}$, the concentration at zero time or at a distance from the bubble; $K, k^{\prime} x$ (concentration of reduced hemoglobin in whole blood) and $k^{\prime}$. the reaction velocity constant for the association of $\mathrm{O}_{2}$ and reduced hemoglobin to form oxyhemoglobin. $K$ or $K^{*}$ is identically zero in plasma in which no chemical reaction takes place. It should be noted that equation (1) satisfies the mass diffusion equation of dissolved gas in whole blood or plasma (for $K=0$ )

$$
\frac{\partial C}{\partial t}=\frac{D}{r^{2}} \frac{\partial}{\partial r}\left(r^{2} \frac{\partial C}{\partial r}\right)-K C
$$

subject to the appropriate initial and boundary conditions

$$
\begin{aligned}
C(r .0) & =C_{x} \\
C(x, t) & =C x, C(R, t)=C_{S} . \\
\rho \frac{\mathrm{d} R}{\mathrm{~d} t} & =D\left(\frac{\partial C}{\partial r}\right)_{r \cdot R} .
\end{aligned}
$$

In order that the $(-K C)$ term may describe the mass consumption of the dissolved gas resulting from a first-order chemical reaction between the dissolved gas and hemoglobin, the concentration of hemoglobin must remain constant during the process of chemical reaction. The situation is observed during the early stage of bubble collapse, or when the gas bubble is in relative motion with respect to whole blood.
By solving equation (1) with $K=0$ corres ponding to the case in which no chemical reaction takes place between the dissolved gas and the liquid. Epstein and Plesset (1950) have obtained the analytical result for the prediction of bubble lifetime, $t_{f}$, i.e. the time for complete dissolution of a bubble, as

$$
t_{f}^{*}=\frac{1}{4 \pi Q^{2}} \exp \left[\frac{2 Q \cos ^{-1} Q}{\left(1-Q^{2}\right)^{1 / 2}}\right]
$$

wherein $t_{f}^{*}=D t_{f} / R_{0}{ }^{2}$ and $Q=\left(C_{p}^{*}-C_{\infty}^{*} / 2 \pi\right)^{1 / 2}$. Equation (4) will be employed to determine the gas diffusivity in plasma using the experimental data of $t_{f}$ and $R_{0}$. The usefulness of equation (4) for predicting mass diffusivity was borne out in its agreement with the values given in the literature for oxygen and nitrogen in water.

The reaction velocity constant between the dissolved oxygen and the reduced hemoglobin in whole blood will be determined by equation (1). utilizing the mass diffusivity of the dissolved oxygen in plasma as $D$.

\section{APPARATUS}

Measurements of the rates at which a gas bubble is absorbed by plasma or blood were made through two steps. The first step was to degas the liquid. During this stage, the gas dissolved in plasma is removed and some oxyhemoglobin in whole blood dissociates into reduced hemoglobin and oxygen, which was removed as soon as it is formed. The occurence of dissociation of some oxyhemoglobin is evidenced by a change in the color of the blood from scarlet to purple. The second step involved the injection of a gas bubble into the degassed blood or plasma, followed by the measurements of the bubble size at certain time intervals until the bubble was completely dissolved in the liquid.

The equipment used in the degassing process is shown in Fig. 1. The test fluid is placed in a $250 \mathrm{ml}$ separatory funnel which has an opening on one end and a stop cock on the opposite end. A rubber stopper is attached to 


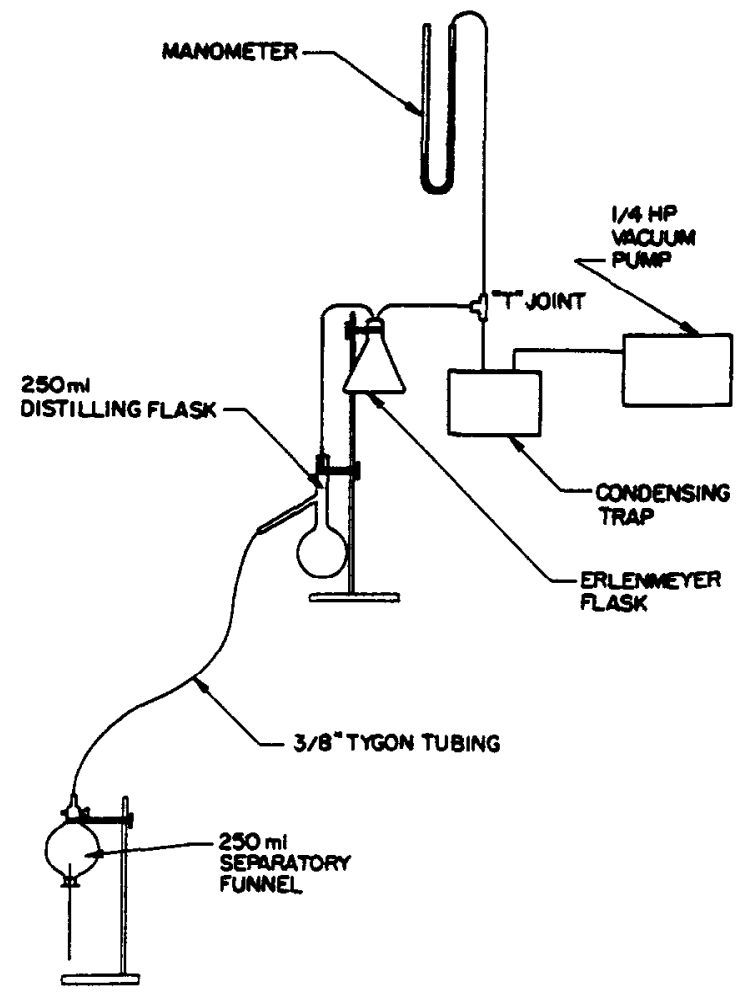

Fig. 1. Apparatus for degassing process.

the open end. A thermometer is inserted into the fluid through a hole in the rubber stopper. During the degassing process the funnel attached to a stand is positioned with the stop cock at the top. A $1 \mathrm{~m}$ length of $\frac{3}{8}$ in. diameter tygon tubing leads from the stop cock of the funnel to a $250 \mathrm{ml}$ distilling flask, which traps fluid being carried out of the funnel during the degassing process. A $50 \mathrm{~cm}$ length of tubing leads from the top of the distilling flask to a $250 \mathrm{ml}$ Erlenmeyer flask which retains any fluid being transported up the tubing from the distilling flask. A $50 \mathrm{~cm}$ length of tubing from the Erlenmeyer flask is connected to a ' $T$ ' joint. One branch of the ' $T$ ' leads to a mercury manometer. while the other branch is connected to a condensing trap. The condensing trap removes much of the water vapor from the air being drawn from the system. A $2 \mathrm{~m}$ length of $\frac{3}{8}$ in. diameter tubing leads from the condensing trap to a $\frac{3}{3}$ horsepower $\mathrm{Hy}$-vac vacuum pump. A vacuum of approximately $28.5 \mathrm{in}$. of mercury is obtained during the degassing process.

The equipment used in injection and measurement of bubble size is illustrated in Fig. 2 . The liquid in the separatory funnel serves as the medium for the diffusion of the gas bubble. The gas is drawn into a syringe with a size number 20 needle. The needle is inserted through the rubber stopper in the funnel and a small bubble is introduced into the liquid. The bubble is observed through the wall of the funnel placed on the side on a wooden support which allows the illumination of the funnel from be-

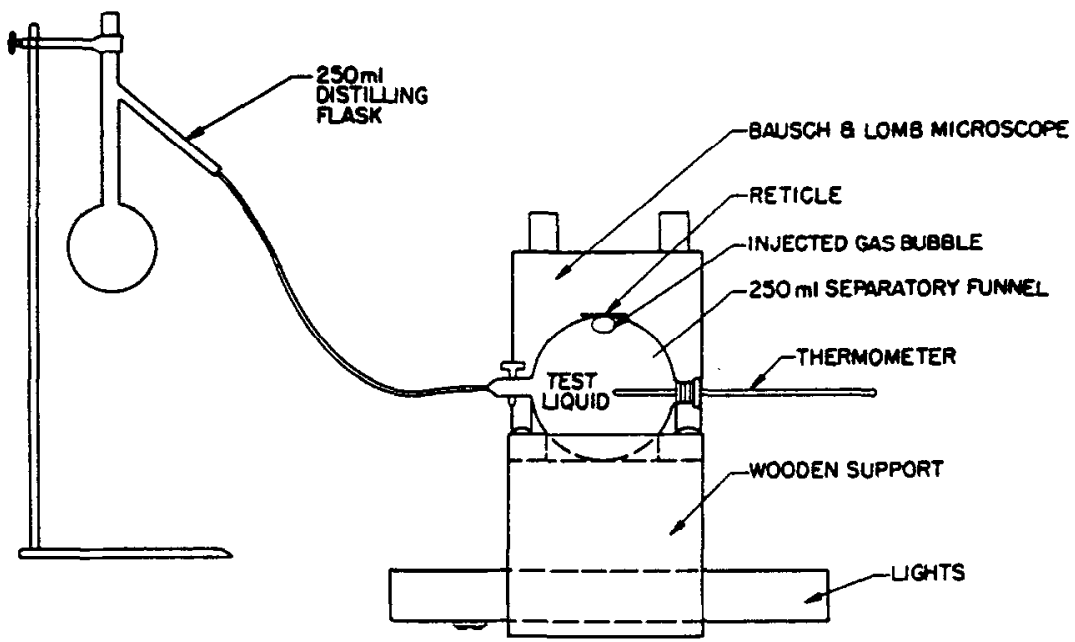

Fig. 2. Bubble measurement set up. 
neath. The illumination is provided by two $15 \mathrm{~W}$ white florescent lamps. An Edscorp No. 30186 reticle is placed on the side of the funnel. The reticle has a $10 \mathrm{~mm}$ long metric scale devided into units of $0.2 \mathrm{~mm}$. A dual eye-piece Bausch and Lomb microscope is placed above the funnel and reticle. The bubble size is observed under a magnification of $10 \cdot 5 \times$.

The liquid viscosity is measured using the test apparatus depicted in Fig. 3. Measuring the liquid viscosity provides a means of detecting any change in the physical properties of the liquid during testing. The test liquid placed in a $3.4 \mathrm{~cm}$ i.d. $14 \mathrm{~cm}$ long glass tube is allowed to flow through a capillary tube $16 \mathrm{~cm}$ long into a $100 \mathrm{ml}$ boiling flask. The time required for the liquid to fill the spherical

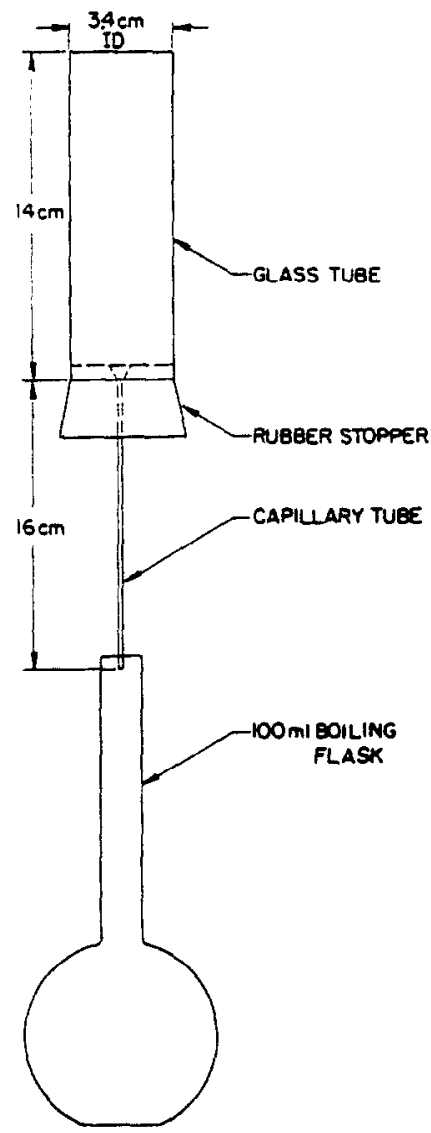

Fig. 3. Apparatus for viscosity measurement. portion of the flask is recorded. The measurements are conducted before and after each bubble test. A change in the time required to fill the flask to the chosen level indicates a proportional change in liquid viscosity. A substantial change in liquid viscosity may indicate the deterioration of the biological fluid and thus will influence the rate of dissolution of the gas bubble.

\section{EXPERIMENTAL PROCEDURE}

The experiment begins with the degassing of the test liquid. Two stands are used, one to hold the separatory funnel and the other to hold the distilling flask and the Erlenmeyer flask, as illustrated in Fig. 1. The base of the second stand is placed about $76 \mathrm{~cm}$ above that of the first stand. The level of the Erlenmeyer flask is approximately $35 \mathrm{~cm}$ above that of the distilling flask. The positioning of the containers at different levels allows much of the liquid transported into the tubing to flow back into its original container. $200 \mathrm{ml}$ of liquid is placed in the separatory funnel and in the distilling flask. The vacuum pump is turned on until the bubbles formed during the pumping process fill the containers and the tubing above the containers. Then, the pump is turned off until the liquid transported by the rapid bubbling in the containers has settled back into the original container. The on-andoff operation of the pump is repeated until the bubbling rate becomes low enough that the transportation of the liquid from the separatory funnel has ceased. The pump is then left running to complete the degassing process. After a bubble has been injected and absorbed during the testing of diffusion rate the pumping is resumed prior to another bubble injection. The second degassing requires about 15 min. For plasma, the pumping times for the first run and subsequent runs are $12 \mathrm{hr}$ and $1 \mathrm{hr}$, respectively. In case of dog blood, these pumping times are $10 \mathrm{hr}$ and $1 \mathrm{hr}$, respectively. It was observed that bubbling processes diminished in approximately $8 \mathrm{hr}$. 
The vacuum pressure is read off the mercury manometer.

When the degassing is complete. the vacuum pump is turned off. Liquid in the distilling flask is transferred back to the separatory funnel through the tubing connecting the two containers. The distilling flask is inclined and the liquid is allowed to run down the connecting tube. The pouring is continued until the liquid has filled half the length of the tubing leading to the separatory funnel. Then, the tubing leading from the condensing trap to the vacuum pump is disconnected at the condensing trap. The pressure in the flasks returns to the ambient pressure. The rubber stopper is removed from the distilling flask, which is now moved to the top of the second stand. The separatory funnel is removed from the first stand and placed on the wooden support as shown in Fig. 2. A gas bubble is then injected through the rubber stopper into the degassed liquid in the separatory funnel. The bubble diameter is measured at $10 \mathrm{~min}$ intervals. The time, bubble diameter and liquid temperature are recorded. The equipment is returned to the arrangement depicted in Fig. 1, after the gas bubble is completely dissolved in the liquid. The level of the liquid in both the separatory funnel and distilling flask are adjusted to contain $200 \mathrm{ml}$ of liquid before next run is started.

Because of rapid bubble shrinkage due to chemical reaction between the dissolved gas and reduced hemoglobin immediately following the injection of a bubble, the initial phase of bubble-size history was recorded using a movie camera. When the camera was in position, its lens was fitted with a fine scale which rests on the surface of the flask above the gas bubble. The developed movie film was then projected onto a screen. A recording device consisting of a linear potentiometer, battery and storage-type oscilloscope was used to continuously record the diameter of the bubble projected on the screen. The recording device functioned in the following way. Two indicating arms attached to the potentiometer body and shaft, respectively, were employed to measure the instantaneous diameter of the bubble. Then, an output voltage proportional to the distance between the two arms was generated across the poles of the potentiometer. This signal was transmitted by cable into the oscilloscope. As the indicating arms were manipulated to follow the diameter of the shrinking bubble which was continuously projected on the screen, a continuous but time-varying potentiometer voltage was generated. The voltage signal produced a continuous locus of the tracing beam on the oscilloscope. The slope of the trace on the oscilloscope which represented the speed of bubble shrinkage during the initial phase was measured.

The viscosity of the liquid is measured periodically, to check any possible change in the liquid property resulting from the degassing process of its continuous exposure to the room temperature and pressure. The liquid viscosity is selected as a yardstick for two reasons. One reason is that mass diffusivity is inversely proportional to the liquid viscosity under isothermal condition, Bird et al. (1962). The other reason is that the liquid viscosity is very sensitive to any chemical or physical change in biological fluids.

\section{RESULTS AND DISCUSSION}

When a gas dissolves in a liquid, the concentration of the gas in the liquid is directly proportional to the partial pressure of the gas, according to Henry's law. The solubility of gases in liquids, $C_{S}$, is generally expressed in terms of the Bunsen absorption coefficient, which is defined as the volume of gas at S.T.P. dissolved by a unit volume of the liquid, when there is a partial pressure of the gas of $1 \mathrm{~atm}$. It is known (Fenn et al. 1964), that of the total amount of oxygen carried by the blood, less than 5 per cent is found to be in simple physical solution. Therefore, reversible chemical reaction is responsible for the remainder or at least 95 per cent of the dissolved 
oxygen. However, a normal value for the $P_{0_{\mathrm{a}}}$ of arterial blood is $100 \mathrm{~mm} \mathrm{Hg}$ or $100 / 760 \mathrm{~atm}$. Hence, the total oxygen content of $100 \mathrm{ml}$ of equilibrated blood at $37^{\circ} \mathrm{C}$ and $760 \mathrm{~mm} \mathrm{Hg}$ is $0.285 \mathrm{ml}$ at $P_{0_{2}}$ of $95 \mathrm{~mm} \mathrm{Hg}$. Since 55 per cent of blood is plasma, the solubility of oxygen in $100 \mathrm{ml}$ of plasma is

$$
(0.285 \mathrm{ml}) \frac{(760 \mathrm{~mm} \mathrm{Hg})}{(95 \mathrm{~mm} \mathrm{Hg})} \frac{100}{55}=4.15 \mathrm{ml}
$$

For oxygen density of $1.305 \times 10^{-3} \mathrm{~g} / \mathrm{cm}^{3}$, this is equivalent to $C_{S}=5.42 \times 10^{-5} \mathrm{~g} / \mathrm{cm}^{3}$. The solubility of oxygen in water under the same conditions is $3.22 \times 10^{-5} \mathrm{~g} / \mathrm{cm}^{3}$. Thus, the ratio of the solubilities in blood and water is 1.68. Since no data are available for the solubility of oxygen in plasma as a function of temperature, it will be assumed for the estimation of the solubility in plasma that this ratio remains the same over a certain temperature range close to $37^{\circ} \mathrm{C}$.

In the experiments, oxygen bubbles are dissolved in completely degassed plasma (corresponding to $C_{\infty}=0$ ). The initial bubble radius and the time of complete dissolution were measured, and are illustrated in Table 1. The values of the bubble lifetime $t_{f}^{*}$ are calculated from equation (4). The diffusivity is then determined from the definition of $t_{f}^{*}$. The liquid temperature averaged over an entire run is also given in Table 1 for reference. The results shown in Table 1 indicate the dependency of mass diffusivity on the liquid temperature.

Like oxygen, carbon dioxide is another gas that dissolves in blood during the respiration function of the blood. In the survey of the literature related to gas embolism, Chan et al.
(1969) have noted that the use of carbon dioxide gas to flood the operation field has been widely recommended for open-heart surgery because of its higher solubility in water than air or oxygen. This method seems to be in popular use nowadays. With these applications the experiments were conducted to determine the diffusivity of carbon dioxide in plasma. When carbon dioxide diffuses into the plasma, several types of chemical reactions take place simultaneously. Therefore, the values of the diffusivity illustrated in Table 2 include the effects of these chemical reactions on the diffusion of carbon dioxide in plasma. These diffusivities were determined by equation (4) through the following steps.

The total content of carbon dioxide at $P_{\mathrm{CO}_{2}}=40 \mathrm{~mm} \mathrm{Hg}$ in $100 \mathrm{ml}$ of plasma at $37^{\circ} \mathrm{C}$ and $760 \mathrm{~mm} \mathrm{Hg}$ is $3.0 \mathrm{ml}$. Since 55 per cent of blood is plasma and the density of carbon dioxide is $1.81 \times 10^{-3} \mathrm{gm} / \mathrm{cm}^{3}$, the solubility of carbon dioxide in plasma is $1.88 \times 10^{-4}$ $\mathrm{gm} / \mathrm{cm}^{3}$. The ratio of the solubilities of carbon dioxide in plasma and water is then equal to $1.88 \times 10^{-4} / 1.04 \times 10^{-3}$ or 0.181 . This ratio is employed to evaluate the solubility of carbon dioxide in plasma at different temperature, by multiplying the ratio by the solubility of carbon dioxide in water at the corresponding temperature. Although the value of the diffusivity thus determined is not a true indication of mass diffusivity for carbon dioxide, it will be useful in the quantitative evaluation of gas embolism due to carbon dioxide.

Table 3 presents the mass diffusivities of nitrogen in degassed plasma.

Next, the reaction velocity constants between the dissolved oxygen and reduced hemo-

Table 1. Mass diffusivity of oxygen in degassed plasma

\begin{tabular}{cccccccc}
\hline $\begin{array}{c}R_{0} \times 10^{2} \\
(\mathrm{~cm})\end{array}$ & $\begin{array}{c}t_{f} \\
(\mathrm{sec})\end{array}$ & $\begin{array}{c}C_{3} \times 10^{3} \\
\left(\mathrm{~g} / \mathrm{cm}^{3}\right)\end{array}$ & $\begin{array}{c}\rho \times 10^{3} \\
\left(\mathrm{~g} / \mathrm{cm}^{3}\right)\end{array}$ & $C_{p}^{*} \times 10^{*}$ & $t_{f}^{*}$ & $\begin{array}{c}D \times 10^{6} \\
\left(\mathrm{~cm}^{2} / \mathrm{sec}\right)\end{array}$ & $\begin{array}{c}T \\
\left({ }^{\circ} \mathrm{C}\right)\end{array}$ \\
\hline 3.35 & 1080 & 7.35 & 1.38 & 5.31 & 7.2 & 7.47 & 19.5 \\
$4 \cdot 1$ & 1442 & 6.18 & 1.344 & 4.60 & 8.4 & 9.49 & 28.7 \\
5.4 & 2592 & 6.28 & 1.346 & 4.66 & 8.3 & 9.35 & 27.9 \\
8.0 & 5580 & 6.65 & 1.36 & 4.89 & 7.9 & 9.06 & 24.6 \\
\hline
\end{tabular}


Table 2. Mass diffusivity of carbon dioxide in degassed plasma

\begin{tabular}{lccccccc}
\hline $\begin{array}{c}R_{0} \times 10^{2} \\
(\mathrm{~cm})\end{array}$ & $\begin{array}{c}t_{f} \\
(\mathrm{sec})\end{array}$ & $\begin{array}{c}C_{s} \times 10^{4} \\
\left(\mathrm{~g} / \mathrm{cm}^{3}\right)\end{array}$ & $\begin{array}{c}\rho \times 10^{3} \\
\left(\mathrm{~g} / \mathrm{cm}^{3}\right)\end{array}$ & $C_{\phi}^{*} \times 10$ & $t_{f}^{*}$ & $\begin{array}{c}D \times 10^{s} \\
\left(\mathrm{~cm}^{2} / \mathrm{sec}\right)\end{array}$ & $\begin{array}{c}T \\
\left({ }^{\circ} \mathrm{C}\right)\end{array}$ \\
\hline 3.5 & 990 & 3.09 & 1.92 & 0.169 & 1.9 & 2.34 & 19.5 \\
5.0 & 1404 & 2.79 & 1.89 & 0.148 & 2.2 & 3.92 & 22.9 \\
6.0 & 2298 & 2.52 & 1.88 & 0.134 & 2.5 & 3.91 & 26.3 \\
7.25 & 3048 & 2.41 & 1.86 & 0.130 & 2.55 & 4.39 & 28.0 \\
\hline
\end{tabular}

Table 3. Mass diffusivity of nitrogen in degassed plasma

\begin{tabular}{cccccccc}
\hline $\begin{array}{c}R_{0} \times 10^{2} \\
(\mathrm{~cm})\end{array}$ & $\begin{array}{c}t_{f} \\
(\mathrm{sec})\end{array}$ & $\begin{array}{c}C_{s} \times 10^{5} \\
\left(\mathrm{~g} / \mathrm{cm}^{3}\right)\end{array}$ & $\begin{array}{c}\rho \times 10^{3} \\
\left(\mathrm{~g} / \mathrm{cm}^{3}\right)\end{array}$ & $C_{\rho}^{*} \times 10^{2}$ & $t_{f}^{*}$ & $\begin{array}{c}D \times 10^{6} \\
\left(\mathrm{~cm}^{2} / \mathrm{sec}\right)\end{array}$ & $\begin{array}{c}T \\
\left({ }^{\circ} \mathrm{C}\right)\end{array}$ \\
\hline 7.0 & 8.520 & 4.06 & 1.15 & 3.53 & 11.0 & 6.33 & 23.5 \\
6.0 & 7.200 & 4.10 & 1.16 & 3.53 & 11.0 & 5.50 & 21 \\
5.5 & 5.100 & 4.15 & 1.165 & 3.56 & 11.0 & 6.53 & 19.7 \\
3.0 & 1.500 & 4.10 & 1.16 & 3.53 & 11.0 & 6.60 & 21.2 \\
\hline
\end{tabular}

globin will be determined for human and dog bloods. Since the values of $K^{*}$ in bloods range from $10^{3}-10^{4}$, the second term on the right side of the equation (1) becomes negligible compared with the other terms in the bracket in a short time, say $1 \mathrm{sec}$, following the injection of the bubble. Neglecting the second term and approximating $\operatorname{erf}\left(\sqrt{ } K^{*} t^{*}\right)$ as unity, equation (1) can be simplified as

$$
\frac{\mathrm{d} R^{*}}{\mathrm{~d} t^{*}}=-C_{\rho}^{*}\left(1-C_{\infty}^{*}\right)\left(\frac{1}{R^{*}}+\sqrt{ } K^{*}\right) \text {. }
$$

The reaction velocity constant $K^{*}$ or $K$ can be determined by equation (5) with the initial rate of dissolution $\mathrm{d} R^{*} / \mathrm{d} t^{*}$, and the initial radius $R^{*}$ obtained experimentally using a movie camera and a recording device. Table 4 illustrates the values of the reaction velocity constant thus determined from three typical runs. They are compared with those available in the literature by Fenn et al. (1964). At $37^{\circ} \mathrm{C}$, the reaction velocity constants are found to be $26 \cdot 7 / \mathrm{sec}$ determined by rapid reaction techniques by Hartridge and Roughton (1923) and $9.76 / \mathrm{sec}$ based on the half time of the rate of reaction of hemoglobin in red cell values. In view of the accuracy of the results and the simplicity in both the apparatus and experimental technique, the present method is indeed very attractive.

Likewise, the reaction velocity constant between oxygen and reduced hemoglobin in dog blood was found to be about the same order of magnitude as that in human blood.

Table 4. Reaction velocity constants between oxygen and reduced hemoglobin in degassed human blood

\begin{tabular}{|c|c|c|c|c|c|}
\hline \multicolumn{4}{|c|}{ Present method } & \multicolumn{2}{|c|}{$\begin{array}{l}\text { Reference [14] } \\
K \text { in } \sec ^{-1} \text { at } 37^{\circ} \mathrm{C}\end{array}$} \\
\hline$\underset{(\mathrm{mm})}{R}$ & $\begin{array}{c}\mathrm{d} R / \mathrm{d} t \\
(\mathrm{~mm} / \mathrm{sec})\end{array}$ & $\begin{array}{c}K \\
\left(\sec ^{-1}\right)\end{array}$ & $\begin{array}{c}T \\
\left({ }^{\circ} \mathrm{C}\right)\end{array}$ & $\begin{array}{l}\text { Rapid reaction } \\
\text { techniques }\end{array}$ & $\begin{array}{l}\text { Based on } \\
\text { half-time }\end{array}$ \\
\hline $\begin{array}{l}0.49 \\
0.18 \\
0.17\end{array}$ & $\begin{array}{l}0.0257 \\
0.0233 \\
0.0230\end{array}$ & $\begin{array}{l}24 \cdot 2 \\
21 \cdot 1 \\
20 \cdot 2\end{array}$ & $\begin{array}{l}20 \\
17 \\
17\end{array}$ & $26 \cdot 7$ & $9 \cdot 76$ \\
\hline
\end{tabular}




\section{CONCLUSION}

The apparatus, experimental technique and data analysis described above have been applied to determine the mass diffusivities of oxygen, carbon dioxide and nitrogen in plasma. The accuracy of the results obtained by the present method is borne out in the agreement with those reported in the literature for the diffusion of oxygen and nitrogen in water, Wotton et al. (1970). The method is also extended to determine the reaction velocity constant between oxygen and reduced hemoglobin in both the human and dog bloods. The results agree well with that obtained by the rapid reaction techniques, but are somewhat larger than that obtained by the measurement of the half-time of the rates of reaction of hemoglobin in red cell suspensions.

Acknowledgements - This study was supported by a grant (grant number 1 ROI HE 12708) and a Biomedical Science Research support Grant (FR-07050: Dr. A. G. Norman is the project director) both from the National Institute of Health for which the authors are grateful.

\section{REFERENCES}

Barcroft. H.. Davson. H. and Paton. W. D. M. (Editors) (1964) Transport and diffusion in red blood cells. Williams and Wilkins. Baltimore.

Bird, R. B., Stewart, W. E. and Lightfoot, E. N. (1962). Transport Phenomena. Part 3. Wiley, New York.

Brandstaetter, F. (1952) Bemerkungen uber $\mathrm{H}$. Maches Methode fur Bestimmung des Diffusionskoeffizienten von Luft in Wasser. Akademie der Wissenschaften, Wien, Mathematische Naturwissenschaftlische Klasse 161. 107-130.

Chan, K. S. and Yang, W. J. (1969) Survey of literature pertinent to the problems of gas embolism in human body. J. Biomechanics 2, 299-312.

Davenport. H. W. (1958) The ABC of acid-base chemistry. University of Chicago Press, Chicago, U.S.A.

Epstein. P. S. and Plesset, M. S. (1950) On the stability of gas bubbles in liquid-gas solutions. J. appl. Phys. 18 , 1505-1509.

Fenn, W. O. and Rahn. H. (Editors) (1964) Handbook of Physiology. Sect. 3; Respiration, Vol. 1. Chaps. 32 and 34. Amer. Physiol. Soc.. Washington. D.C.

Gibson. Q. H. (1954) Stopped-flow apparatus for the study of rapid reactions. Discuss. Faraday Soc. 17 , $137-139$.

Gibson. Q. H. (1959) The kinetics of reactions between hemoglobin and gases. Prog. Biophys. biophys. Chem. 9. 1-53.

Hartridge, H. and Roughton, F. J. W. (1923) A method of measuring the velocity of very rapid chemical reactions. Proc. R. Soc. A104, 376-394.

Hartridge, H. and Roughton. F. J. W. (1925) The kinetics of haemoglobin. III. The velocity with which oxygen combines with reduced hemoglobin. Proc. R. Soc. A107, 654-683.

Houghton, G. Pitchie. P. D. and Thomson. J. A. (1962) The rate of solution of small stationary bubbles and the diffusion coefficients of gases in liquids. Chem. Engng Sci. 17, 221-227.

Liebermann. L. (1957) Air bubbles in water. J. appl. Phys. 28, 205-211.

Mache, H. (1929) Uber die Diffusion and Ubergang von Gasen in Flussingkeiten. Akademie der Wissenschaften, Wien, Mathematische Naturwissenschaftlische Klasse 138. 529-556.

Manley, D. M. J. P. Change of size of air bubbles in water containing a small dissolved air content. $B . J$. appl. Phys. 11.38-42.

Millikan. G. A. (1933) A simple photographic calorimeter. J. Physiol., Lond. 79, 152-158.

Wotton. D. R.. Yang, W. J and Echigo, R. (1970) Review and modification of experimental rechnique to determine gas diffusivity in liquids. Proceedings of the ASME Sth Symposium on Thermophysical Properties, 313-318.

Yang. W. J. (1970) Dynamics of gas bubbles in whole blood and plasma. J. Biomechanics 4. 119.

\section{NOMENCLATURE}

$C$ concentration of dissolved gas in liquid; $C_{S}$, at saturated state; $C_{\infty}$, at zero time or at a distance from bubble

$C^{*} \quad C / C_{s} ; C_{\infty}^{*} \cdot C_{\infty} / C_{S} ; C_{\rho}^{*}, C_{s} / \rho$

$D$ diffusion coefficient

$k^{\prime}$ reaction velocity constant for the association of $\mathrm{O}_{2}$ and reduced hemoglobin to form oxyhemoglobin

$K k^{\prime} x$ (concentration of reduced hemoglobin in whole blood)

$K^{*} \quad K R_{0} \geqslant / D$

$r$ distance from the center of spherical bubble

$R$ bubble radius: $R_{0}$, at zero time

$R^{*} \quad R / R_{0}$

1 time

If bubble life time

$t^{*} D t / R_{0}{ }^{2}$

$\rho$ density of gas inside bubble 